\title{
A Polymerase Chain Reaction Based DNA Fingerprinting Technique: Amplified Fragment Length Polymorphism for Molecular Typing of Perchlorate Reducing Bacteria
}

\author{
Anita Shete ${ }^{1}$, Vikram Ghole², Manju Raina3 ${ }^{3}$, Bikash Aich ${ }^{1}$ \\ ${ }^{1}$ Aavanira Biotech Pvt. Ltd., Pune, India \\ ${ }^{2}$ Department of Biochemistry, University of Pune, Pune, India \\ ${ }^{3}$ Ministry of Environment \& Forests, New Delhi, India \\ Email: anitamicro@yahoo.com
}

Received 17 July 2014; revised 14 August 2014; accepted 2 September 2014

Copyright (C) 2014 by authors and Scientific Research Publishing Inc.

This work is licensed under the Creative Commons Attribution International License (CC BY).

http://creativecommons.org/licenses/by/4.0/

(c) (i) Open Access

\begin{abstract}
Genetic profiling of environmentally important organisms is very essential for easy identification of biodegrading bacteria. In the previous study, we have reported the perchlorate biodegrading bacteria and characterized them by biochemical analysis and $16 \mathrm{~S}$ sequencing. We have observed a very similar isolates of Arthrobacter (Actinobacteria) degrading 4.1 $\mathrm{mM}$ and $4.7 \mathrm{mM}$ of ammonium perchlorate [1]. In this study, we report PCR based DNA fingerprinting technique to generate the genomic signature of these closely related group of Arthrobacter species. This study also effectively generates unique genomic signature for each of these isolates that has potential for use in molecular monitoring as well as for tracking genomic variation and rearrangements.
\end{abstract}

\section{Keywords}

AFLP-Amplified Fragment Length Polymorphism, Arthrobacter, Ammonium Perchlorate, Bio-Degradation

\section{Introduction}

With advent of the concept of microbes coming into rescue of environmental pollution, there has been an in-

"Corresponding author.

How to cite this paper: Shete, A., Ghole, V., Raina, M. and Aich, B. (2014) A Polymerase Chain Reaction Based DNA Fingerprinting Technique: Amplified Fragment Length Polymorphism for Molecular Typing of Perchlorate Reducing Bacteria. Journal of Environmental Protection, 5, 1111-1115. http://dx.doi.org/10.4236/jep.2014.512109 
creasing demand for genetic profiling of such organisms. It has been observed that similar biochemical properties are linked to organisms of similar genetic makeup. Marginal superiority that is observed between closely related strains is often due to few significant genetic variations that exist within each of these similar strains.

Maintaining different strains of an economically important microbe has got its own significance. It not only allows conservation of genetic pool but also assists an environmentalist in carefully choosing them for different purposes such as effluent process management, production of bacterial products, etc. [2] [3]. However, a conventional method of morphology, morphometry and biochemistry offers limited depth up to which discrimination between two closely related microbes can be done. This eludes a microbiologist who is compelled to label microbes of different genetic get-up under a single taxon thus preventing the scientific community from understanding and exploiting the genetic heterogeneity of microbes that occur at deeper levels.

Molecular typing has been used previously to identify and trace dissemination of pathogenic and spoilage bacteria associated with food processing. Amplified fragment length polymorphism (AFLP) is a novel DNA fingerprinting technique which is considered highly reproducible and has high discriminatory power.

The objective of this study to characterizes and evaluates perchlorate reducing microbes collected from natural flora and also to ascertain their true position in the phylogenetic ladder. This is accomplished through generation of DNA based identity profiles that assists in differentiating one isolate from the other as well as establishes a unique molecular signature for each one of the isolates that has diverse applications.

This paper therefore details an advanced method of DNA fingerprinting and is intended for differentiating the three related strains of microbes used in this study along with generation of unique molecular signature for each one of them. One of the spin-offs of this study is ascertaining of the similarity coefficient/genetic distance within these strains which is of relevance in understanding the diversity that is prevalent in the micro flora.

Amplified fragment length polymorphism (AFLP) is a genetic mapping technique that uses the process of selective amplification of restriction-enzyme digested DNA fragments to generate a unique fingerprint for a particular genome. The power of an AFLP analysis system is derived from its ability to quickly generate a large number of marker fragments for any organism, without prior knowledge of the genomic sequence.

AFLP analysis has proven to be an effective research tool for discriminating DNA samples from a variety of bacterial species and strains [4]-[8].

\section{Materials and Methods}

\subsection{Isolation and Purification of DNA}

Three different isolates of perchlorate degrader's viz., A1, A2 and A3 were identified for the study. Pure cultures obtained by streak plate method and were maintained in Nutrient agar plates.

A single colony of freshly grown isolate viz., A1, A2 and A3 was inoculated in sterile nutrient Broth and incubated for 24 hrs. under shaking conditions at $100 \mathrm{rpm}$. The culture was then centrifuged at $4000 \mathrm{rpm}$ for 10 min to obtain the cell pellet. One hundred and ninety microliter $(\mu \mathrm{l})$ of Tris EDTA buffer and $10 \mu \mathrm{l}$ lysozyme (10 $\mathrm{mg} / \mathrm{ml}$ ) was added and incubate at $37^{\circ} \mathrm{C}$ for 30 minutes. It was followed by addition of $10 \mu \mathrm{l}$ of $10 \%$ SDS. The resulting solution was mixed well and to it added $2 \mu \mathrm{l}$ of Proteinase K (stock solution: $20 \mathrm{mg} / \mathrm{ml}$ ). Mixed well and incubated at $37^{\circ} \mathrm{C}$ for one hour. $25 \mathrm{ul} \mathrm{CTAB} / \mathrm{NaCl}$ mix was added and incubated at $65^{\circ} \mathrm{C}$ for $10 \mathrm{~min}$. Equal volume of chloroform isoamyl alcohol was added. Centrifuged at 10,000 rpm for $10 \mathrm{~min}$. Supernatant was separated and 2/3rd volume of isopropanol was added (approximately $500-700 \mu \mathrm{l}$ ) and kept at $4^{\circ} \mathrm{C}$ for $1 \mathrm{hr}$. Mixture of above reagents was centrifuged at 10,000 rpm for $10 \mathrm{~min}$. DNA spool was collected in a new tube. It was further washed with $1 \mathrm{ml}$ of 70\% ethanol and again centrifuged at 10,000 rpm for $10 \mathrm{~min}$. DNA pellet was air dried and dissolved in $25 \mu$ sterile Milli Q water.

To check the quality of isolated DNA, the samples were run on a $0.8 \%$ agarose gel and the DNA was visualized by ethidium bromide staining under UV trans-illuminator. Also DNA was quantified by recording Optical Density (OD) at $260 \mathrm{~nm}$. Approximately 100 - $400 \mathrm{ng}$ of DNA were used for AFLP analysis.

\subsection{Digestion of DNA and Ligation with Adapters}

The AFLP protocol followed was similar to that described by [9]. The DNA was first digested using TaqI (5 units in a $10-\mu \mathrm{l}$ volume, $2 \mathrm{hr}$. at $65^{\circ} \mathrm{C}$ ), followed by Eco RI (5 units in a $20-\mu \mathrm{l}$ volume, $2 \mathrm{~h}$ at $37^{\circ} \mathrm{C}$ ). The Eco RI and TaqI adapters (Table 1) were then ligated on to the digested DNA using T4 DNA ligase (1 unit in a 10 ul 
Table 1. Oligonucleotide primers used in the study.

\begin{tabular}{|c|c|c|}
\hline Adapters & Name & Sequence \\
\hline Adapters Eco RI & $\begin{array}{l}\text { Eco R1 top strand } \\
\text { Eco R1 bottom strand }\end{array}$ & $\begin{array}{l}\text { 5’-CTCGTAGACTGCGATCC-3’ } \\
\text { 5’-AATTGGTACGCAGTCTAC-3’ }\end{array}$ \\
\hline Adapters TaqI & $\begin{array}{c}\text { Taq top strand } \\
\text { Taq bottom strand }\end{array}$ & $\begin{array}{l}\text { 5'-GACGATGAGTCCTGAC-3' } \\
\text { 5'-CGGTCAGGACTCAT-3' }\end{array}$ \\
\hline Primers Eco RI & $\begin{array}{l}\text { E01 } \\
\text { E32 } \\
\text { E33 } \\
\text { E35 } \\
\text { E38 } \\
\text { E39 } \\
\text { E42 } \\
\text { E44 } \\
\text { E45 }\end{array}$ & $\begin{array}{l}\text { 5'-GAC TGC TA ATT CA -3', } \\
\text { 5'-GAC TGC TA ATT CAA C-3' } \\
\text { 5'-GAC TGC TA ATT CAA G-3', } \\
\text { 5'-GAC TGC TA ATT CAC A-3', } \\
\text { 5'-GAC TGC TA ATT CAC T-3' } \\
\text { 5'-GAC TGC TA ATT CAG A -3' } \\
\text { 5'-GAC TGC TA ATT CAG T -3' } \\
\text { 5'-GAC TGC TA ATT CAT C-3', } \\
\text { 5'-GAC TGC TA ATT CAT G -3' }\end{array}$ \\
\hline Primers TaqI & $\begin{array}{l}\text { T01 } \\
\text { T02 } \\
\text { T32 } \\
\text { T33 } \\
\text { T35 } \\
\text { T38 } \\
\text { T48 } \\
\text { T49 } \\
\text { T50 } \\
\text { T51 }\end{array}$ & $\begin{array}{c}\text { 5'-GAT GAG TCC TGA CCG AA-3', } \\
\text { 5'-GAT GAG TCC TGA CCG AC-3' } \\
\text { 5'-GAT GAG TCC TGA CCG AAA C-3' } \\
\text { 5'-GAT GAG TCC TGA CCG AAA G-3' } \\
\text { 5'-GAT GAG TCC TGA CCG AAC A-3' } \\
\text { 5'-GAT GAG TCC TGA CCG AAC T-3', } \\
\text { 5'-GAT GAG TCC TGA CCG ACA C-3', } \\
\text { 5'-GAT GAG TCC TGA CCG ACA G-3' } \\
\text { 5'-GAT GAG TCC TGA CCG ACC T -3' } \\
\text { 5'-GAT GAG TCC TGA CCG ACC A c-3' }\end{array}$ \\
\hline
\end{tabular}

reaction volume, $3 \mathrm{~h}$ at 37 Degree Celsius generating template DNA for PCR amplification. The ligated mixture was diluted 10 times using sterilized MilliQ water.

\subsection{Amplification of Ligated DNA}

The PCR amplification consisted of two steps: 1) Pre amplification and 2) selective amplification.

\subsection{Pre-Amplification}

$5 \mu$ of the ligated DNA was added to a $25 \mu$ l PCR reaction mix containing Buffer, MgCL 2 (25 mM) dNTP's (0.2 $\mathrm{mM}$ of each), Taq polymerase (1 unit) \& Eco RI and TaqI primers carrying one selective nucleotide (50 ng of each). The Eco RI primer sequence was 5'-GAC TGC GTA CCA ATT CA-3' and the TaqI primer sequence was 5'-GAT GAG TCC TGA CCG AC-3’.

Samples were subjected to 30 pre-amplification cycles (30 seconds at $94^{\circ} \mathrm{C}, 60$ seconds at $50^{\circ} \mathrm{C}$ and 60 seconds at $72^{\circ} \mathrm{C}$ ).

\subsection{Selective Amplification}

$5 \mu \mathrm{l}$ of the diluted pre-amplification solution was added to a $12.5 \mu \mathrm{l}$ PCR reaction mix containing $10 \times$ buffer, $\mathrm{MgCl}_{2}$ (1.5 mM), dNTP's (0.2 mM of each) Taq polymerase (1 unit), labeled Eco RI selective primer (5 ng), TaqI selective primer (30 ng).

Details of the oligonucleotide primers employed in the study are shown in Table 1.

Adapters and primers used in AFLP analysis (Table 1).

\section{Data Analysis}

For analysis of the data, the anonymous markers obtained through AFLP were recorded in a digital fashion [presence as + (plus) and absence as - (minus)] Phylogeny Inference Program package, Version 3.6a [10] was used for further analysis of the data-sets.

One thousand bootstrapped data were generated through "Seqboot" and distance matrix was calculated using 
the "Restdist" program. The data thus generated were fed into "Neighbor" program and the output files were used to run the "Consensus" algorithm. The resulting data was analyzed using in "Treeview" program (DM Roderic; http://taxonomy.zoology.gla.ac.uk) as a phylogenetic tree with the number of boot strapped data marked which align with trend of the grouping generated through the above analysis.

\section{Results}

Even if ribosomal analysis could effectively differentiate genus Pseudomonas from other two isolates, these two isolates could not be effectively differentiated on the basis of $16 \mathrm{~S}$ ribosomal RNA analysis. One of the disadvantage and shortcoming of ribotyping as a tool to identify known microbe is its strong and obligatory dependence on archived information in the public/private domain. We were interested to know the genetic dissimilarity between isolate A2 and A3 in order to justify the need for maintaining both the strains as source for two different gene pools. This warranted detailed genome analysis. We were apprehensive about the polymorphic information content that would be generated from the popular RAPD study and therefore chose AFLP as the preferred tool for genome analysis.

AFLP [11] [12] provides the option for using the advantages of RAPD coupled with extended stringency imposed through high annealing temperature during the thermal cycling process. The technique has provision of scanning the whole genome for polymorphism screened through carefully chosen amplification primers.

The method involves prior enrichment of genome fragments, generated through dual-enzyme restriction, with a set of pre-amplification primers (forward and reverse) each bearing a decisive single base over-hang that results in 16 fold reduction in the number of fragments amplified. Thus an extra base is sufficient for analysis of a bacterial genome.

Following primary enrichment of the EcoR 1 and TaqI fragment with the pre-amplification primers bearing 3' single base overhang "G" and "C" for primers annealing to the EcoR 1 and TaqI adapters respectively, 24 different primer combinations were identified for final amplification, each with three base overhangs.

Having a robust and reliable electrophoresis system that can generate reproducible profiles is crucial to the success of the AFLP assay. The Applied Biosystems 3130 series Genetic Analyzers are fully automated, highperformance, fluorescence-based, multi-capillary systems that can run 4 samples. Sample analysis on these instruments is fully automated, from the moment each 96 well plate is placed on the instrument and the run is initiated. The systems provide continuous, unattended operation, from automated polymer loading and sample injection to separation, detection, and data generation.

When the Auto analysis feature of GeneMapper ${ }^{\circledR}$ software is used for data analysis, the system offers true one button operation from sample loading to data analysis. GeneMapper ${ }^{\circledR}$ software can also generate a table containing AFLP marker genotypes. The software uses advanced analysis algorithms that can rapidly and accurately identify common and polymorphic peaks among large number of samples.

We used the Unweighted Pair Group Method of Arithmetic means (UPGMA) method for clustering of the isolates. It is the simplest methods of clustering taxa based on similarity. It assumes an evolutionary clock whereby changes are believed to have accumulated at a constant rate among all three lineages. The most similar taxa are assumed to have diverged most recently and are typically clustered at the tip of the tree. On the other hand, the most divergent taxa are assumed to originate at the earliest and therefore emerge from the base of the tree. One of the side effects of the clock assumption is polarization of the phylogenetic tree, which therefore becomes rooted in structure and concept. With regard to our study on isolate grouping, it was assumed that changes in sequence that is reflected in loss or creation of primer binding site, has occurred in approximately the same rate in all the three isolates. This is, in fact, the assumption of a molecular clock. If the rate of change is approximately constant, then the isolate that differ by few changes (in other words, by few amplicon fragments) must have diverged from a common ancestor recently. The isolate that differ by most amplicon must have diverged from a common ancestor long ago. Positioning the deepest divergence in terms of percent difference in amplicon profile at the base of the tree effectively roots it. The "consense" program of PHYLIP (3.6a) was run in "majority rule consensus" mode where the tree consisted of all groups that occurred more than $50 \%$ of the time.

Appearance of a value at the node edge of the phylogenetic tree indicates the number of trees generated from 1000 bootstrap values that align with the consensus tree generated by the program.

In this study, distance matrixes that were transformed to represent a phylogenetic tree, following data bootstrapping at a value of 1000 , could be categorized into three different types. 


\section{Conclusions}

From this study, we concluded that A2 and A3 in spite of belonging to identical genus with rudimentary differences in $16 \mathrm{~S}$ ribosomal sequence were significantly distanced from each other. This in turn puts weight to the view that they are unique source of two different gene pools bearing apparently similar characters of perchlorate reduction. This study also effectively generates unique genomic signature for each of these isolates that has potential for use in molecular monitoring as well as for tracking genomic variation and rearrangements.

One of the useful outcomes of this study is emergence of a list of vetted AFLP primer combination with known potential for generating polymorphic information from such microbes.

\section{Acknowledgements}

Authors would like to thank ISRO (Indian space research organization) providing funds, Genom Biotech Pvt. Ltd. and Molecular Biology Laboratory, Division of Biochemistry, Department of Chemistry, University of Pune, India, for providing infrastructure facility.

\section{References}

[1] Shete, A.M., Mukhopadhyaya, P.N., Acharya, A., Aich, B.A., Joshi, S. and Ghole, V.S. (2008) Aerobic Reduction of Perchlorate by Bacteria Isolated in Kerala, South India. Journal of Applied Genetics, 49, 425-431. http://dx.doi.org/10.1007/BF03195643

[2] Skidmore, R., Leach, C., Hoffman, J., Amos, W. and Aldridge, D. (2010) Conservation Genetics of the Endangered Depressed River Mussel, Pseudanodonta complanata, Using Amplified Fragment Length Polymorphism (AFLP) Markers. Aquatic conservation: Marine and freshwater ecosystems. Aquatic Conservation: Marine and Freshwater Ecosystems, 20, 560-567. http://dx.doi.org/10.1002/aqc.1131

[3] Lind, E.E. and Grahn, M. (2011) Directional Genetic Selection by Pulp Mill Effluent on Multiple Natural Populations of Three-Spined Stickleback (Gasterosteus aculeatus). Ecotoxicology, 20, 503-512. http://dx.doi.org/10.1007/s10646-011-0639-8

[4] Geornaras, I., Kenene, N.F., von Holy, A. and Hastings, J.W. (1999) Amplified Fragment Length Polymorphism Fingerprinting of Pseudomonas Strains from a Poultry Processing Plant. Applied and Environmental Microbiology, 5, 3828-3833.

[5] Jackson, P.J., Hill, K.K., Laker, M.T., Ticknor, L.O. and Keim, P. (1999)Genetic Comparison of Bacillus anthracis and Its Close Relatives Using Amplified Fragment Length Polymorphism and Polymerase Chain Reaction Analysis. Journal of Applied Microbiology, 87, 263-269. http://dx.doi.org/10.1046/j.1365-2672.1999.00884.x

[6] Janssen, P., Coopman, R., Huys, G., et al. (1996) Evaluation of the DNA Fingerprinting Method AFLP as a New Tool in Bacterial Taxonomy. Microbiology, 142, 1881-1893. http://dx.doi.org/10.1099/13500872-142-7-1881

[7] Lin, J., Kuo, J. and Ma, J. (1996) A PCR-Based DNA Fingerprinting Technique: AFLP for Molecular Typing of Bacteria. Nucleic Acids Research, 4, 3649-3650. http://dx.doi.org/10.1093/nar/24.18.3649

[8] Vos, P., Hogers, R., Bleeker, M., et al. (1995) AFLP: A New Technique for DNA Fingerprinting. Nucleic Acids Research, 23, 4407-4414. http://dx.doi.org/10.1093/nar/23.21.4407

[9] Ajmone-Marsen, P., Valentini, A., Cassandro, M., Vecchiotti-Antaldi G., Bertoni, G. and Kuiper, M (1997) AFLP Markers for DNA Fingerprinting in Cattle. Animal Genetics, 28, 418-426. http://dx.doi.org/10.1111/j.1365-2052.1997.00204.x

[10] Felsenstein, J. (2001) PHYLIP Phylogeny Inference Package. Version 3.6 (Alpha2), Department of Genetics, University of Wasington, Seattle.

[11] Zabeau, M. and Vos, P. (1993) Selective Restriction Fragment Amplification: Ageneral Method for DNA Fingerprinting. Publication 0534858 Al. European Patent Office, Munich.

[12] Vos, P. and Kuiper, M. (1996) AFLP. In: Caetano-Anolles, G. and Gresshoff, P.M., Eds., DNA Markers: Protocols, Applications and Overviews, J. Willey and Sons Inc., Bognor Regis. 
Scientific Research Publishing (SCIRP) is one of the largest Open Access journal publishers. It is currently publishing more than 200 open access, online, peer-reviewed journals covering a wide range of academic disciplines. SCIRP serves the worldwide academic communities and contributes to the progress and application of science with its publication.

Other selected journals from SCIRP are listed as below. Submit your manuscript to us via either submit@scirp.org or Online Submission Portal.
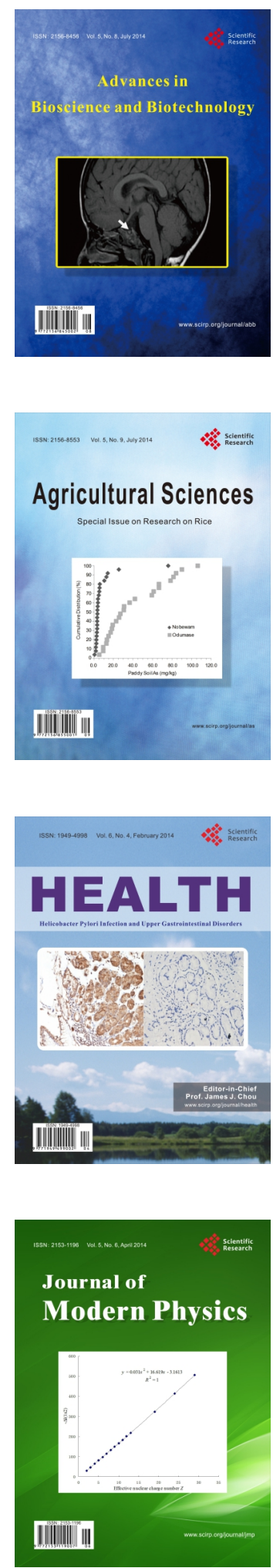
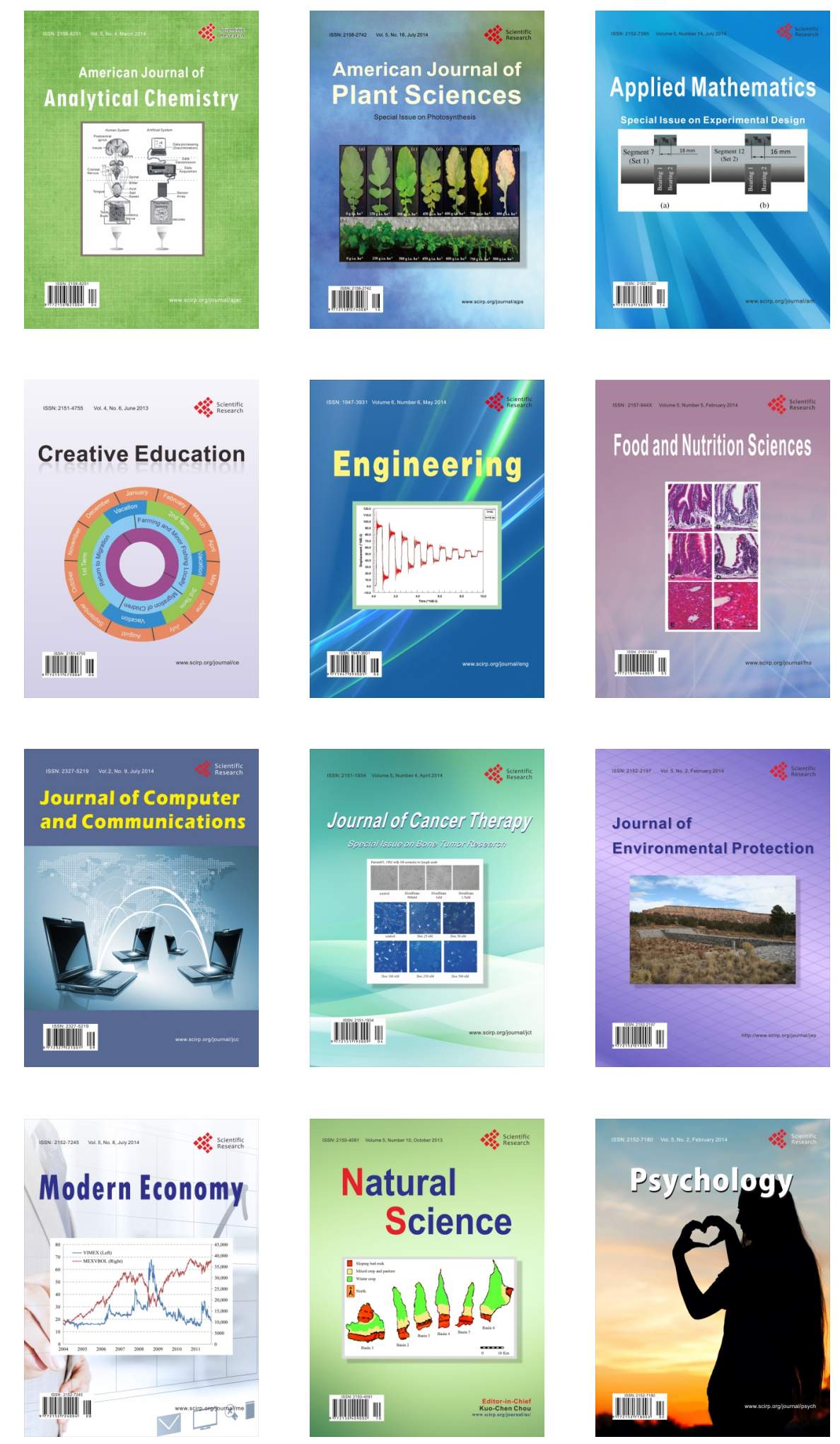